\title{
Fourier Transform Luminescence Spectroscopy of Semiconductor Thin Films and Devices
}

J.D. Webb, B.M. Keyes, R.K. Ahrenkiel, M.W. Wanlass, K. Ramanathan, L.M. Gedvilas, M.R. Olson, P. Dippo, and K.M. Jones

Presented at the $3^{\text {rd }}$ International Symposium on Advanced Infrared and Raman Spectroscopy (AIRS III); July 5-9, 1998; Vienna, Austria Accepted for publication in:

Vibrational Spectroscopy (Elsevier Science)

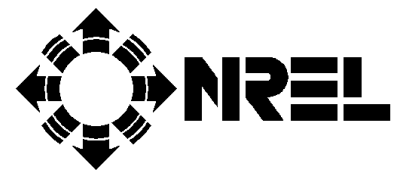

National Renewable Energy Laboratory 1617 Cole Boulevard Golden, Colorado 80401-3393

A national laboratory of the U.S. Department of Energy Managed by Midwest Research Institute for the U.S. Department of Energy under contract No. DE-AC36-83CH10093

Prepared under Task Nos. PV803101 and WU6H0205 


\begin{abstract}
NOTICE
This report was prepared as an account of work sponsored by an agency of the United States government. Neither the United States government nor any agency thereof, nor any of their employees, makes any warranty, express or implied, or assumes any legal liability or responsibility for the accuracy, completeness, or usefulness of any information, apparatus, product, or process disclosed, or represents that its use would not infringe privately owned rights. Reference herein to any specific commercial product, process, or service by trade name, trademark, manufacturer, or otherwise does not necessarily constitute or imply its endorsement, recommendation, or favoring by the United States government or any agency thereof. The views and opinions of authors expressed herein do not necessarily state or reflect those of the United States government or any agency thereof.
\end{abstract}

Available to DOE and DOE contractors from:

Office of Scientific and Technical Information (OSTI)

P.O. Box 62

Oak Ridge, TN 37831

Prices available by calling 423-576-8401

Available to the public from:

National Technical Information Service (NTIS)

U.S. Department of Commerce

5285 Port Royal Road

Springfield, VA 22161

703-605-6000 or 800-553-6847

or

DOE Information Bridge

http://www.doe.gov/bridge/home.html 


\title{
Fourier Transform Luminescence Spectroscopy of Semiconductor Thin Films and Devices
}

\author{
J. D. Webb*, B. M. Keyes, R. K. Ahrenkiel, M. W. Wanlass, K. Ramanathan, \\ L. M. Gedvilas, M. R. Olson, P. Dippo, and K. M. Jones \\ National Renewable Energy Laboratory \\ 1617 Cole Blvd. \\ Golden, CO 80401-3393 USA
}

\begin{abstract}
We have been successful in adapting Fourier transform (FT) Raman accessories and spectrophotometers for sensitive measurements of the photoluminescence (PL) spectra of photovoltaic materials and devices. In many cases, the sensitivity of the FT technique allows rapid room-temperature measurements of weak luminescence spectra that cannot be observed using dispersive PL spectrophotometers. We present here the results of a number of studies of material and device quality obtained using FT-luminescence spectroscopy, including insights into bandgap variations, defect and impurity effects, and relative recombination rates. We also describe our approach to extending the range of the FT-Raman spectrophotometer to cover the region from 11,500 to $3700 \mathrm{~cm}^{-1}$, enabling FTluminescence measurements to be made from 1.42 to $0.46 \mathrm{eV}$, and our investigation of FT-PL microspectroscopy.
\end{abstract}

\section{Introduction}

Thin semiconductor films are used in high-efficiency photovoltaic (PV) and thermophotovoltaic (TPV) devices for commercial, space, military, and residential markets. PV devices typically convert visible and near-infrared (NIR) radiation in sunlight to electricity, while TPV devices convert NIR radiation supplied by thermal emissive sources to electricity. The semiconductor films under investigation for use in PV and TPV devices include the II-VI and III-V compound semiconductors. Photoluminescence spectroscopy is used extensively to characterize semiconductor thin films. For example, NIR PL spectroscopy has been used to detect light- or heat-induced defects ("dangling bonds") in hydrogenated amorphous silicon [1] and has been correlated with the efficiency of PV devices produced from copper indium diselenide (CuInSe ${ }_{2}$, or CIS) thin films [2]. Time-resolved (TR) NIR PL spectroscopy has been used to measure the minority carrier lifetimes $\tau$ in $\mathrm{Al}_{x} \mathrm{Ga}_{1-\mathrm{x}} \mathrm{As}$ [3] and to optimize the design of highefficiency, AlGaAs-passivated GaAs solar cells [4]. Although some of this work has been done at room temperature, detection of weak NIR PL emission beyond the wavelength range of Si and photomultiplier detectors when using dispersive spectrophotometers has typically required cryogenic cooling of semiconductor samples $[1,2]$. Cooling reduces the rate of nonradiative recombination, reduces thermal band broadening, and enhances the intensity of PL emission in semiconductors [1,2].

Fourier transform infrared (FTIR) spectroscopy offers substantial improvements in the analysis of weak signals over dispersive spectroscopy through Jacquinot's throughput advantage [5]. A variety of PL measurements, with FTIR detection that exploits this advantage, have been reported on semiconductors such as GaAs [6], GaInAs [7], and porous silicon [8]. Rowell [9] reports FTIR-assisted PL measurements on a variety of NIR PL emitters, and reviews the advantages and limitations of the 
technique. More recent work has involved the use of FT-Raman accessories with FTIR spectrophotometers to obtain room-temperature and cryogenic PL and electroluminescence (EL) spectra from a variety of bulk and thin-film semiconductor materials having PV applications [10-13].

Semiconductor PV materials analyzed in the recent work include silicon, germanium, and $1-3-\mu \mathrm{m}$ films of $\mathrm{CuInSe}_{2}$ (CIS), $\mathrm{Cu}[\mathrm{In}, \mathrm{Ga}] \mathrm{Se}_{2}$ (CIGS), GaInAs, GaInAsP, InPAs, and gallium arsenide-germanium alloy (GaAsGe) on various substrates. The room-temperature PL analyses of CIS, CIGS, and GaAsGe films reported for the first time in this work were made possible by the sensitivity of the FT-PL technique.

Use of a dedicated FT-Raman spectrophotometer for FT-luminescence measurements, as described in the present work, is advantageous because FT-Raman spectrophotometers contain goldcoated reflective optics to enhance collection of weak NIR emission. Also, luminescence processes occur with quantum efficiencies many orders of magnitude higher than that for the Raman scattering process, which for NIR excitation is of the order of $10^{-6}[14]$. The dedicated FT-Raman instruments are so sensitive to the comparatively strong NIR PL signals that excitation power had to be reduced to submilliwatt levels in some cases to avoid detector saturation. The capability to obtain PL spectra at low excitation power also minimizes band filling and sample heating artifacts [13].

Problems that were addressed using FT-PL spectroscopy, alone or in combination with other analytical techniques, have included junction formation and surface passivation in CIGS PV devices [13] and determination of the bandgap and the strain-induced effects on material quality in GaInAs TPV epitaxial films [15]. In CIGS devices using $\mathrm{CdS}$ or $\mathrm{ZnO}$ buffer layers, the $\mathrm{p} / \mathrm{n}$ active junction resides at or near the buffer/CIGS interface [16]. Insights into the nature and location of the junction in CIGS PV devices are introduced in the present work. Also presented will be a brief summary of our efforts to characterize $\mathrm{Ga}_{\mathrm{x}} \mathrm{In}_{1-\mathrm{x}} \mathrm{As}$ TPV devices and device analog structures.

\section{Experimental}

\subsection{Samples}

Films of CIGS $2.5 \mu \mathrm{m}$ in thickness and having the composition $23.4 \% \mathrm{Cu}, 19.3 \% \mathrm{In}, 6.8 \% \mathrm{Ga}$, and $50.4 \%$ Se were prepared by elemental coevaporation onto $\mathrm{Mo} / \mathrm{glass}$ substrates at $500^{\circ}-560^{\circ} \mathrm{C}[16]$. The films were subjected to FT-PL spectroscopy, ellipsometry at $632.8 \mathrm{~nm}$, secondary ion mass spectroscopy (SIMS), X-ray photoelectron spectroscopy (XPS), and other surface analysis methods [13]. Several processes were applied individually to a series of the CIGS films, including chemical bath deposition (CBD) and physical vapor deposition (PVD) of 5-nm or 50-nm CdS films, followed in some cases by deposition of 50-nm intrinsic $\mathrm{ZnO}$ films by radio frequency (rf) sputtering (NREL process) [16]. Intrinsic $\mathrm{ZnO}$ films, $50 \mathrm{~nm}$ in thickness, were also applied to CIGS films using chemical vapor deposition (CVD) [17]. The CBD process for CdS film growth consisted of inserting a CIGS/Mo/glass sample into an ammoniated solution of $\mathrm{CdSO}_{4}$, adding thiourea, and heating the $\mathrm{CBD}$ solution over a time interval sufficient to produce the desired CdS film thickness [16]. We also applied two different surface treatments to CIGS film samples. Background solution (BS) treatment of CIGS films consisted of carrying out the CBD process without thiourea. A "BS + thiourea" treatment consisting of the BS procedure followed by a deionized water rinse, and a repetition of the $\mathrm{CBD}$ process without $\mathrm{CdSO}_{4}$, was applied to other CIGS samples. The BS and BS + thiourea treatments left no continuous film of CdS on the CIGS surfaces. The CIGS samples were characterized using surface analysis, ellipsometry, and FTPL spectroscopic analysis [13] after treatment or processing. 
TPV device structures and undoped device analog structures [15] incorporating $\mathrm{Ga}_{\mathrm{x}} \mathrm{In}_{1-\mathrm{x}}$ As layers were grown using metal-organic vapor-phase epitaxy (MOVPE) [18] on InP substrates. The detailed structure of the multilayer $\mathrm{Ga}_{\mathrm{x}} \mathrm{In}_{1-\mathrm{x}} \mathrm{As}$ samples is shown in the figures accompanying the results and discussion. Continuously graded layers (CGL) and step-graded layers (GL) are grown between the absorber and the substrate in lattice-mismatched (LMM) TPV devices to enable epitaxial growth while controlling absorber bandgap by varying $\mathrm{x}$ in the $\mathrm{Ga}_{\mathrm{x}} \mathrm{In}_{1-\mathrm{x}} \mathrm{As}$ films $[15,18]$.

\subsection{Instrumentation}

The FT-PL measurements on CIGS samples were carried out using a Nicolet System 800 FTIR spectrophotometer with an attached FT-Raman accessory and $\mathrm{LN}_{2}$-cooled, Zn-doped Ge detector operated at $4 \mathrm{~cm}^{-1}$ resolution. The internal HeNe reference laser used for interferometer control in the spectrophotometer was fitted with a high-quality bandpass filter to eliminate spectral line artifacts contributed by HeNe plasma emission. The vacuum shroud of a Model R2205 Joule-Thomson (J-T) cryostat from MMR Technologies, Inc. (Mountain View, CA) was miniaturized to provide the reflective FT-Raman optics with a clear aperture sufficient to collect the FT-PL signal. Using high-pressure argon, the J-T cryostat chilled the samples from room temperature to their measurement temperature of $87 \mathrm{~K}$ within about 10 minutes. With a custom gas blend, temperatures as low as $30 \mathrm{~K}$ could be reached. One of two external HeNe lasers equipped with a 632.8-nm bandpass filter and neutral density filters for power control was used for excitation in place of the Nd:YAG laser source provided with the FT-Raman accessory. This allowed the 1064-nm Rayleigh line filters to be removed from the FT-Raman optical train and replaced with a Schott RG-850 long-pass filter, enabling continuous FT-PL spectral measurements to be made over the entire CIGS emission range (up to wavelengths as short as $950 \mathrm{~nm}$ ). Diameter of the HeNe excitation beam, convergent at the focus of the collection optics, was measured using heat-sensitive paint with $\mathrm{T}_{\mathrm{m}}=89^{\circ} \mathrm{C}$ as $100-120 \mu \mathrm{m}$ for one of the two HeNe laser sources used (laser \#2). During FT-PL measurements, power incident on the samples was reduced to $0.15 \mathrm{~mW}$ to provide an excitation density of approximately $10^{14} \mathrm{~cm}^{-3}$ (assuming 100- $\mu \mathrm{m}$ beam diameter), low enough to avoid band-filling shifts in the PL spectra, but high enough to give adequate signal-to-noise ratios in the spectra. At this excitation density, the room-temperature PL emission of some of the untreated CIGS films was too weak to measure. Consequently, we report only the FT-PL measurements of the CIGS films done at $87 \mathrm{~K}$. The FT-PL spectra were instrument-corrected using incandescent lamp radiation reflected from a tube containing potassium bromide at the sample position, and the Nicolet FTRaman correction software. This approach to FT-PL spectroscopy is similar in its use of external laser excitation sources to methods described previously [6-9], except for our utilization of the FT-Raman accessory for PL collection.

The Nicolet 800 FT-Raman system was also used to analyze the $\mathrm{Ga}_{\mathrm{x}} \mathrm{In}_{1-\mathrm{x}} \mathrm{As}$ device analogs at room temperature, using 30-mW Nd:YAG excitation $(1064 \mathrm{~nm})$ from its internal laser source, and an $\mathrm{InSb}$ detector from Graseby Infrared equipped with a cold filter to attenuate $\lambda>2700 \mathrm{~nm}$. The primary difference between this approach and those cited previously [6-9] is the capability for software control of the intensity of the 1064-nm Nd:YAG excitation intensity through a variable neutral density filter, and in the quality of the two Kaiser holographic notch filters. Each of the Kaiser filters offer Rayleigh line rejection of $10^{6}$ and a $50 \% \mathrm{~T}$ bandwidth of $700 \mathrm{~cm}^{-1}$ centered at $9400 \mathrm{~cm}^{-1}(1064 \mathrm{~nm})$, with fairly high transmittance and no interference fringe artifacts between 9000 and $3700 \mathrm{~cm}^{-1}$.

A significantly improved FT-PL system (Fig. 1), based on the Nicolet 960 dedicated FT-Raman spectrophotometer (operated at $8 \mathrm{~cm}^{-1}$ resolution), was used for the measurements on $\mathrm{Ga}_{\mathrm{x}} \mathrm{In}_{1-\mathrm{x}} \mathrm{As}$ devices. The instrument includes a diode-pumped, $\mathrm{Nd}: \mathrm{YVO}_{4}$ excitation laser operating at $1064 \mathrm{~nm}$, 
with air cooling and direct power control via the diode pump lasers, which allows more stable operation than the liquid-cooled, lamp-pumped diode laser used in the 800 system described in the previous paragraph. Also included in the 960 system are an $\mathrm{LN}_{2}$-cooled, $\mathrm{Zn}$-doped Ge detector and $180^{\circ}$ reflective sampling optics in the main sample compartment, which allow larger sample and cryostat sizes. The internal HeNe reference laser is filtered to eliminate plasma emission line artifacts. A scanning, auto-focusing Raman/PL microscope with $1-\mu \mathrm{m}$ positioning precision and video capture for visible light microphotography of samples is a significant improvement over the 800 system, enabling sample micro-positioning and room-temperature microanalysis. A Spectra-Tech 32x Reflachromat reflective objective and an Olympus 100x MS Plan 100 objective enabled microscope excitation spot diameters of $10 \mu \mathrm{m}$ and $1.2 \mu \mathrm{m}$, respectively, as measured using heat-sensitive paint with $\mathrm{T}_{\mathrm{m}}=89^{\circ} \mathrm{C}$. Several features were added to the 960 instrument to extend its capabilities for FT-PL spectroscopy. Its long-wavelength range was extended from $1750 \mathrm{~nm}$ (the Ge detector limit) to $2700 \mathrm{~nm}$ by adding a cold-filtered InSb detector (Graseby Infrared). The cold filter and modifications to the detector transimpedance preamplifier each increased the sensitivity of the $\mathrm{InSb}$ detector at $\lambda<2700 \mathrm{~nm}$ by about a factor of three, for an overall sensitivity enhancement of about an order of magnitude. A Melles-Griot Model 06 DLL 807 GaAs diode laser operated at $847 \mathrm{~nm}$ by a Melles-Griot Model 06 DLD 103

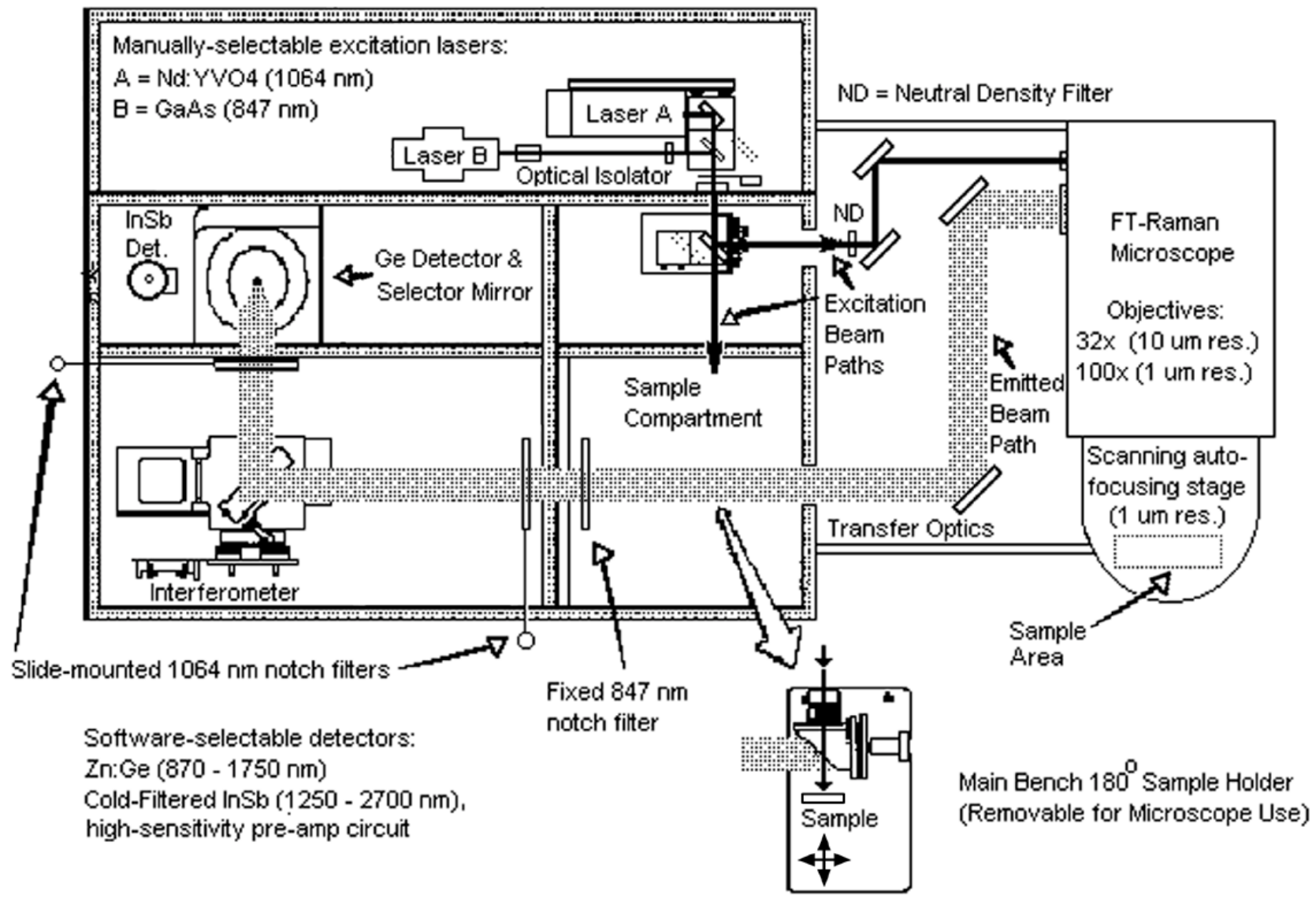

Figure 1. Schematic of Nicolet System 960 FT-Raman spectrophotometer with microscope accessory. The additional laser, detector, and filters added for FT-PL spectroscopy and microspectroscopy are also shown. 
controller was installed in the interlocked instrument housing with an optical isolator. The laser can deliver up to $30 \mathrm{~mW}$ of excitation power to the main sampling compartment. Together with a Kaiser 850-nm holographic notch filter in the emission beam path, the GaAs laser extended the shortwavelength range of the spectrophotometer from $1075 \mathrm{~nm}$ to $870 \mathrm{~nm}$ for PL measurements. Performance of the $850-\mathrm{nm}$ Kaiser filter was similar to that of the 1064-nm filters described previously. Considered together, these modifications extended the range of the FT-Raman spectrophotometer to cover the region from 11,500 to $3700 \mathrm{~cm}^{-1}$, enabling FT-luminescence measurements to be made from 1.42 to $0.46 \mathrm{eV}$. Removable neutral density filters in the main sampling compartment and microscope excitation beam paths enabled low excitation power levels, which are especially important to avoid band filling and sample-overheating effects in FT-PL microspectroscopy because of the small excitation volumes attendant to this technique. The miniature Joule-Thomson cryostat described in the previous paragraph was also adapted to the main sample compartment of the 960 system, providing a sample temperature range from $30 \mathrm{~K}$ to $400 \mathrm{~K}$.

FT-PL microanalysis of the cleaved edges of $\mathrm{Ga}_{\mathrm{x}} \mathrm{In}_{1-\mathrm{x}} \mathrm{As}$ device sample \#1-213 was done at room temperature using the 100x objective and joystick-controlled microscope stage. Excitation power for these measurements was 3-7 $\mathrm{mW}$. To make available a broader region for FT-PL analysis, the sample was angle-lapped. Angle lapping of sample \# 1-213 was done at an angle of $2.5^{\circ}$ to the device plane using a chemical/mechanical polishing medium consisting of $0.05-\mu \mathrm{m}$ non-crystallizing colloidal silica in a buffered ammonia solution that weakly etches GaInAs [19]. This procedure exposed a lapped surface of 180 microns, enabling use of the 32x microscope objective (10- $\mu \mathrm{m}$ excitation spot diameter) to resolve device layers as thin as $\left[10 \mu \mathrm{m} * \sin \left(2.5^{\circ}\right)\right]=0.4 \mu \mathrm{m}$. Automated room-temperature microFT-PL linear scans of the angle-lapped sample were initiated using the Nicolet/Spectra-Tech Atlus mapping software, with 10- $\mu \mathrm{m}$ step sizes, to cover the region from the device surface near the edge of the lapped region to the InP substrate. The 32x microscope objective was used with $20-\mathrm{mW}$ excitation power at $1064 \mathrm{~nm}$ during the linear scans. The instrument correction procedure for the System 960 spectrophotometer main bench and microscope was identical to that described previously for the System 800.

\section{Results and Discussion}

\subsection{CIGS Studies}

The FT-PL system 800 allowed low-noise, well-resolved PL spectra of the treated and untreated CIGS samples to be measured over the entire wavelength range of CIGS emission, with PL intensity measurements repeatable to within $\pm 20 \%$ at a single excitation position on a given sample.

Photoluminescence intensity is directly proportional to the rate of radiative recombination within the absorber material undergoing measurement. This rate is in turn proportional to the photoexcited carrier concentration. Consequently, a significant increase in PL intensity, at constant excitation density, would imply an increase in the photoexcited carrier concentration, or correspondingly, a decrease in the rate of nonradiative recombination. For chemically treated or processed absorber surfaces at which treatment does not change the excitation density, this decrease is described by a reduction in the surface/interface recombination velocity and could result from surface passivation. Removal of surface contaminants, e.g., oxides, which cause band bending at the treated surface could also result in an increase in PL intensity; however, these effects are likely to be minimal for non-uniform surfaces such as the polycrystalline CIGS films [20]. A similar argument could be made that junction formation alone would 
not significantly influence PL intensity in the polycrystalline CIGS films. The processes described in the previous section involve deposition of visible and NIR-transparent CdS films on CIGS surfaces. Surface analysis showed that the CBD process or the BS treatments also result in removal of surface oxide layers $2 \mathrm{~nm}$ in thickness and diffusion of up to 20 at. \% of $\mathrm{Cd}$ to a depth of 5-10 nm into the CIGS surface [21]. These changes may be accompanied by n-type conversion of the normally p-type CIGS surfaces in the Cd-diffused region [21]. The ellipsometric measurements showed that the BS treatments did not result in a significant change in $\alpha$ from its pre-treatment value of $5 \times 10^{-4} \mathrm{~cm}^{-1}$ at $632.8 \mathrm{~nm}$, implying a $1 / \alpha$ penetration depth $\mathrm{L}$ of the order of $0.2 \mu \mathrm{m}$ for above-bandgap radiation in the CIGS films, where $\mathrm{T}_{\text {film }}=\mathrm{e}^{-\alpha \mathrm{L}}$. Earlier work [22] has shown that type conversion does not significantly change $\alpha$ at the bandgap energy $(1.0 \mathrm{eV})$ in CIS single crystals. A significant increase in PL intensity at constant excitation density and energy following processing or treatment therefore implies a reduction in the recombination velocity at the CIGS absorber surface or at the CdS/CIGS interface.

Fig. 2-a shows a series of FT-PL spectra measured using laser \#1 from a bare CIGS film, from a CIGS film exposed to the background solution, and from a CIGS film exposed sequentially to the background solution and to the thiourea solution. The significant increases in PL intensity resulting from either of the two chemical treatments imply a reduction in the surface recombination velocity. The PL intensities measured after either treatment are comparable to each other within the $\pm 50 \%$ variations observed as a function of excitation position on the samples. Fig. 2-b shows a series of FT-PL spectra measured using laser \#1 from a bare CIGS film, CIGS films with 5-nm CBD or PVD CdS layers, and a CIGS film exposed to the background solution before PVD of a 5-nm CdS layer. As with the chemically treated surfaces, deposition of thin CdS layers apparently results in a reduction in the interfacial recombination velocity, with the 5-nm CBD CdS layer giving significantly more improvement than the PVD CdS with or without background solution treatment.

The FT-PL spectra shown in Fig. 2-c were obtained from samples consisting of 50-nm CBD or PVD CdS films plus rf-sputtered $\mathrm{ZnO}$ layers, and from samples consisting of 50-nm ZnO layers applied to CIGS substrates using rf sputtering or CVD. These film thicknesses are typical for CIGS device structures [21], as opposed to the sample structures shown in Figure 2-b. The FT-PL data in Fig. 2-c were taken using laser \#2 and so may not be directly comparable in terms of excitation density with the data in Figs. 2-a and 2-b. Within the set of devices described in Fig. 2-c, the CBD CdS/CIGS device yields by far the highest PL intensity. Scale expansions (not shown) of the data in Figs. 2a, 2-b, and 2-c indicate that application of CBD CdS films or background solutions to CIGS shifted its PL band maxima to shorter wavelengths, while application of PVD CdS or intrinsic ZnO films to the CIGS broadened its PL spectrum towards longer wavelengths [13].

XPS analyses have shown numerous chemical distinctions between CBD and PVD-processed samples [16]. As-deposited CIGS typically exhibits about 10 at. \% of surface sodium, which thermally diffuses from the Mo/glass substrates during CIGS film deposition. The chemical nature of the $\mathrm{Na}$ is not convincingly known, although it is known that the sodium compound oxidizes with exposure to air. Either the CBD process or rinsing with deionized water removes the sodium compound. The background solution contains $\mathrm{Cd}^{+2}$ ions that adsorb at the CIGS surface prior to the addition of thiourea. During CBD, the CdS film forms only after $\mathrm{Cd}^{+2}$ ions adsorb at the CIGS surface. Concurrent SIMS analyses [16] confirm the presence of cadmium on the CIGS surface after background solution treatment, while both cadmium and sulfur are observed on the CIGS surface after background solution/thiourea solution treatment. In contrast, during PVD of CdS films, both cadmium and sulfur impinge simultaneously on the sodium-covered CIGS surface. The PVD process does not incorporate a 
Fig. 2-a

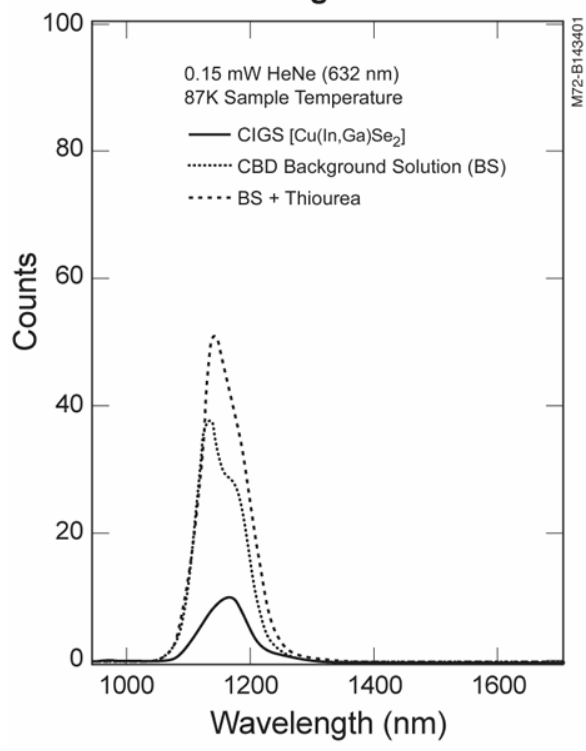

Fig. 2-b

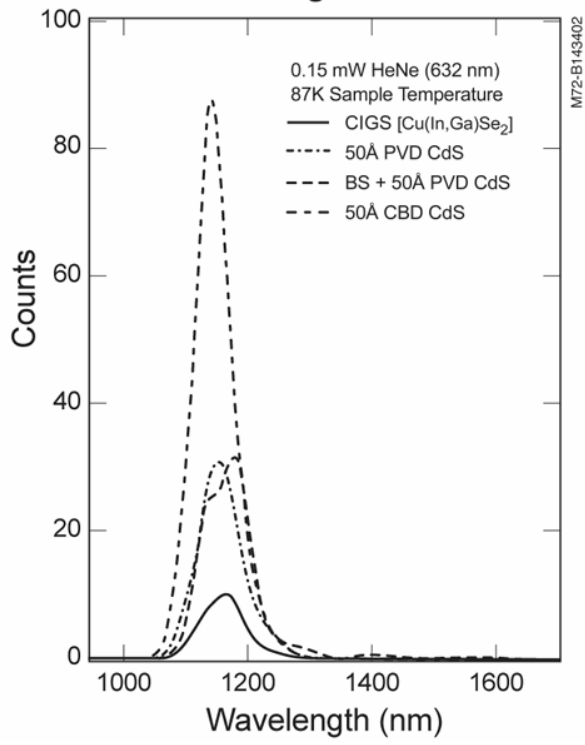

Fig. 2-c

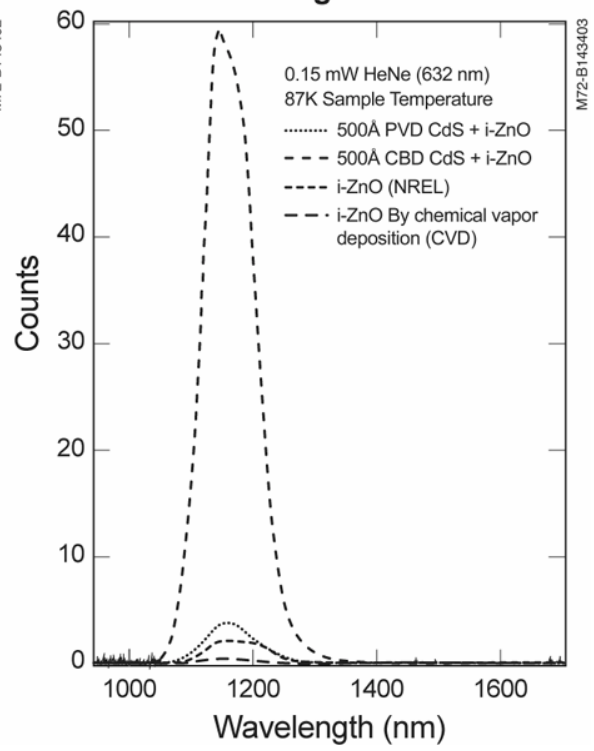

Figure 2. Effect of various surface treatments on CIGS films shown by FT-PL spectroscopy. The surface treatments were solution treatments only (a), CdS film + solution treatment (b), and CdS + ZnO film or ZnO film alone (c).

step to remove the sodium on the CIGS surface. The point is that CdS/CIGS interfaces produced by the $\mathrm{CBD}$ and PVD processes for CdS deposition are different, and these chemical differences have a substantial effect on PL intensity and hence on device performance. The solution treatments confer more than half of the PL intensity enhancement achieved by application of a 5-nm CBD CdS film, which has resulted in the highest efficiencies measured for CIGS devices [13]. It is noteworthy that there is an insignificant difference in PL intensity or energy increases between the background solution and the background solution/thiourea solution treatments of the CIGS films. The components most responsible for the PL enhancements apparently reside in the background solution, which contains $\mathrm{CdSO}_{4}$ and $\mathrm{NH}_{4} \mathrm{OH}$ only. FT-PL spectra (not shown) of $\mathrm{NH}_{4} \mathrm{OH}$-treated CIGS samples show no differences from those of untreated CIGS [21], implying that the cadmium ion present in the CBD process, rather than the removal of surface oxide layers by complexation with ammonia, is responsible for the enhancement in PL intensity. The diffusion of Cd into the CIGS surfaces shown to accompany the solution treatments [21] also supports this hypothesis.

\subsection{GaInAs Studies}

Fig. 3 shows a series of room-temperature FT-PL spectra of undoped $\mathrm{Ga}_{\mathrm{x}} \operatorname{In}_{1-\mathrm{x}} \mathrm{As}$ device analogs on InP substrates. The device analogs incorporate a CGL to reduce LMM strain between the absorber and the InP substrates. The intensity of PL collected from the lattice-mismatched (LMM) $\mathrm{Ga}_{\mathrm{x}} \mathrm{In}_{1-\mathrm{x}} \mathrm{As}$ samples \#2 and \#3 is more than an order of magnitude lower than the intensity of PL collected from the sample (\#1) lattice-matched (LM) to InP, probably mostly because of recombination at mismatchinduced defects [18]. Incorporation of a stepwise GL has been shown to greatly reduce non-radiative recombination rates in a similar device analog sample [18]. The room-temperature PL spectra exhibit considerable broadening relative to low-temperature PL spectra of $\mathrm{Ga}_{\mathrm{x}} \operatorname{In}_{1-\mathrm{x}} \mathrm{As}$ [9], because of thermal band filling [13]. The FWHM bandwidths of the PL spectra are 315, 403, and $339 \mathrm{~cm}^{-1}$ for samples $1-3$, 


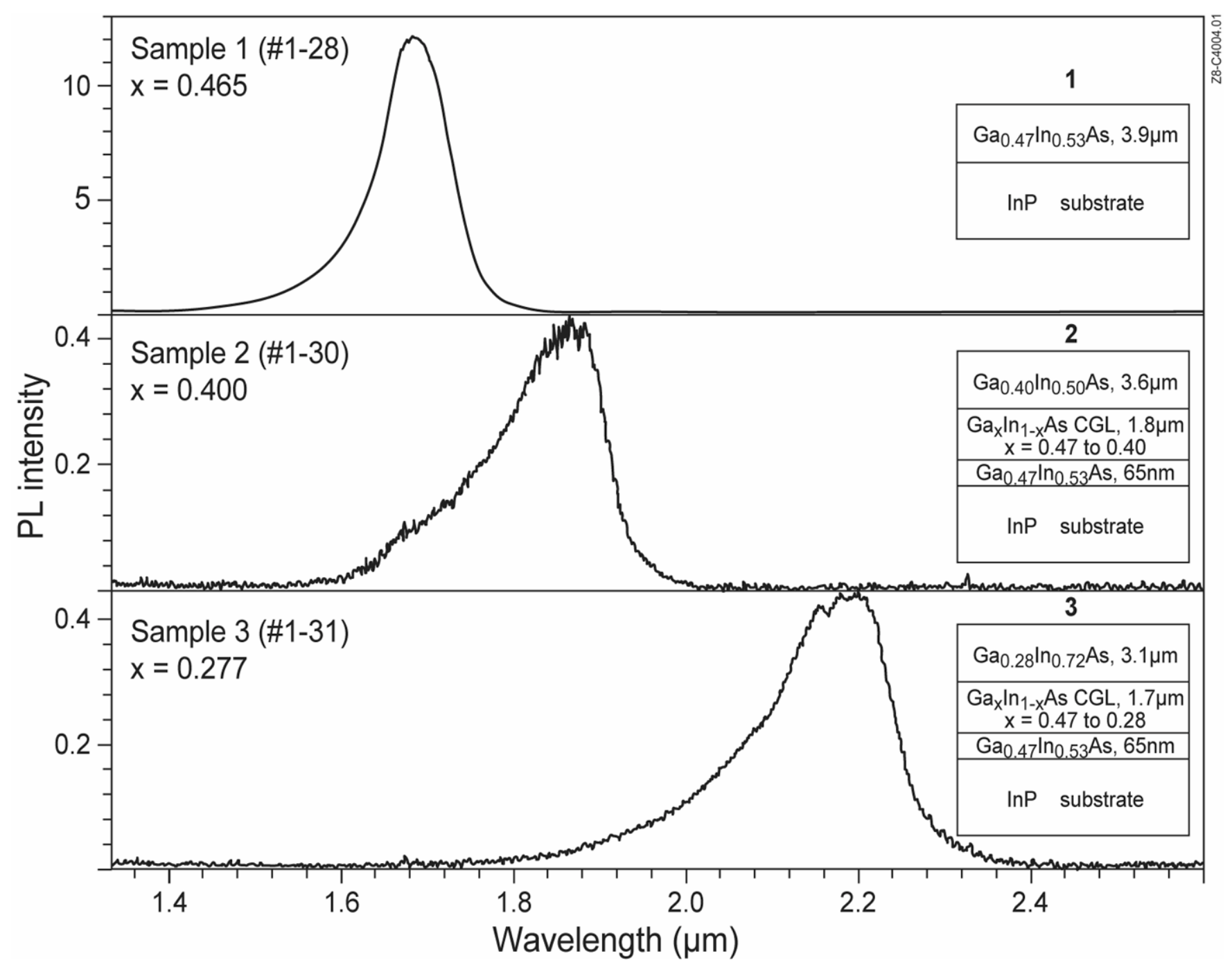

Figure 3. FT-PL spectra and structure of undoped $\mathrm{Ga}_{\mathrm{x}} \mathrm{In}_{1-\mathrm{x}} A \mathrm{As}$ device analogs on InP substrates. The ordinate scales in the plots for sample \#2 and sample \#3 have been expanded for clarity.

respectively. The band broadening observed in the LMM samples relative to the LM sample is probably related to slight compositional variations within the excitation volume of the LMM absorbers.

The compositional redshift of the PL band maxima as $\mathrm{x}$ is decreased from the InP-LM value of 0.47 to 0.28 is within $\mathrm{kT}$ of the predicted bandgap for this material $[18,19]$. These results show that roomtemperature FT-PL spectroscopy is an accurate, sensitive indicator of composition and material quality in $\mathrm{Ga}_{\mathrm{x}} \mathrm{In}_{1-\mathrm{x}}$ As.

In Fig. 4 the structure of TPV device \#1-213 is given. This device contains a LMM p/n $\mathrm{Ga}_{\mathrm{x}} \operatorname{In}_{1-}$ ${ }_{x}$ As absorber layer with a nominal bandgap of $0.6 \mathrm{eV}(\mathrm{x}=0.32)$ and a thickness of $2.3 \mu \mathrm{m}$, and a $\mathrm{Ga}_{\mathrm{x}} \mathrm{In}_{1-}$ ${ }_{x}$ As graded layer with $x$ varying stepwise between 0.32 and 0.47 over a total thickness of $3 \mu \mathrm{m}$, minimizing LMM with the InP substrate. High spatial resolution FT-PL spectra of the cleaved edge of the device were collected at the locations shown in the micrograph, with one spectrum collected in the $\mathrm{Ga}_{\mathrm{x}} \mathrm{In}_{1-\mathrm{x}} \mathrm{As} \mathrm{p} / \mathrm{n}$ absorber layer, and another in the GL near the InP substrate. The PL band maxima are at wavelengths characteristic of $x=0.32$ in the absorber layer and $x=0.47$ in the GL $[18,19]$. The 


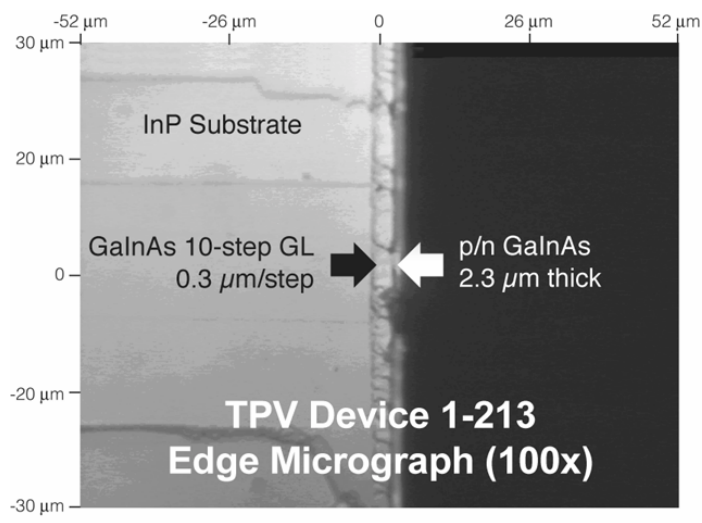

\begin{tabular}{|c|c|}
\hline $\mathrm{p}-\mathrm{Ga}_{0.32} \mathrm{In}_{0.68} \mathrm{As}$ & $30 \mathrm{~nm}$ \\
\hline $\mathrm{p}-\operatorname{In}_{0.32} \mathrm{As}_{0.68} \mathrm{P}$ & $30 \mathrm{~nm}$ \\
\hline $\mathrm{p} / \mathrm{n}-\mathrm{Ga}_{0.32} \mathrm{In}_{0.68} \mathrm{As}$ & $2.3 \mu \mathrm{m}$ \\
\hline $\mathrm{n}-\mathrm{In}_{0.32} \mathrm{As}_{0.68} \mathrm{P}$ & $30 \mathrm{~nm}$ \\
\hline $\begin{array}{l}\mathrm{n}-\mathrm{Ga}_{\mathrm{x}} \ln \mathrm{n}_{1-\mathrm{x}} \mathrm{As} \\
10 \text {-step GL, } \\
\mathrm{X}=0.32 \text { to } 0.47\end{array}$ & $0.3 \mu \mathrm{m} / \mathrm{step}$ \\
\hline InP Substrate & $1.0 \mathrm{~mm}$ \\
\hline
\end{tabular}

TPV Device 1-213 Structure

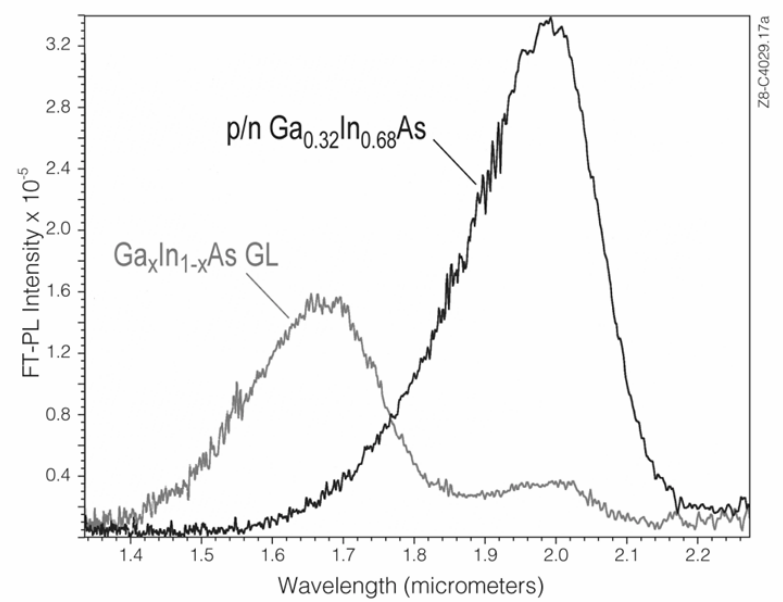

- 100x glass objective gives $1.2 \mu \mathrm{m}$ excitation spot diameter on samples

- Micro-positioning, autofocusing stage gives positioning accuracy to $1 \mu \mathrm{m}$

Figure 4. Micro-FT-PL spectra of the cleaved edge (cross section) of TPV device \#1-213, collected from within the GL and the $p / n$ junction layer at the locations shown in the micrograph of the cleaved device edge, using the $100 x$ objective. The device structure is also shown.

measurement therefore exhibits micron-scale spatial resolution, although some band broadening is evident in the PL spectrum taken in the GL. The FWHM bandwidth is $694 \mathrm{~cm}^{-1}$, compared to $539 \mathrm{~cm}^{-1}$ in the absorber layer. The band broadening of the GL PL spectrum to lower energies is attributable to the GL compositional variation within the excitation area, and possibly to carrier diffusion followed by radiative recombination outside the excitation area but within the objective collection aperture. A higher PL intensity is evident in the PL spectrum of the junction (absorber) layer relative to that of the GL.

Fig. 5 shows the measurement positions of an 18-point FT-PL linear scan (line map) of angle-lapped TPV device \#1-213, superimposed on a micrograph of the lapped device, with a plot of the PL peak intensity measured at the first 17 scan positions also superimposed on the micrograph. The device structure and approximate regions on the lapped surface corresponding to the thickest device layers are also shown. The scan began on the p-GaInAs contact cap layer surface, and progressed through the lapped $\mathrm{p} / \mathrm{n}$ absorber and GL to a final position in the InP substrate. Scan position 10 roughly corresponds to the position of the lower InAsP confinement layer in this double-heterostructure device [23]. A strong, sharp PL spectrum was obtained from the device surface, apparently from the absorber layer through the thin cap and upper confinement layers [23]. The PL intensity dropped to some extent as the absorber layer was traversed during the scan, but stayed relatively high until the GL was approached. It is unlikely that carrier depletion near the junction exerted any effects on the PL intensity 


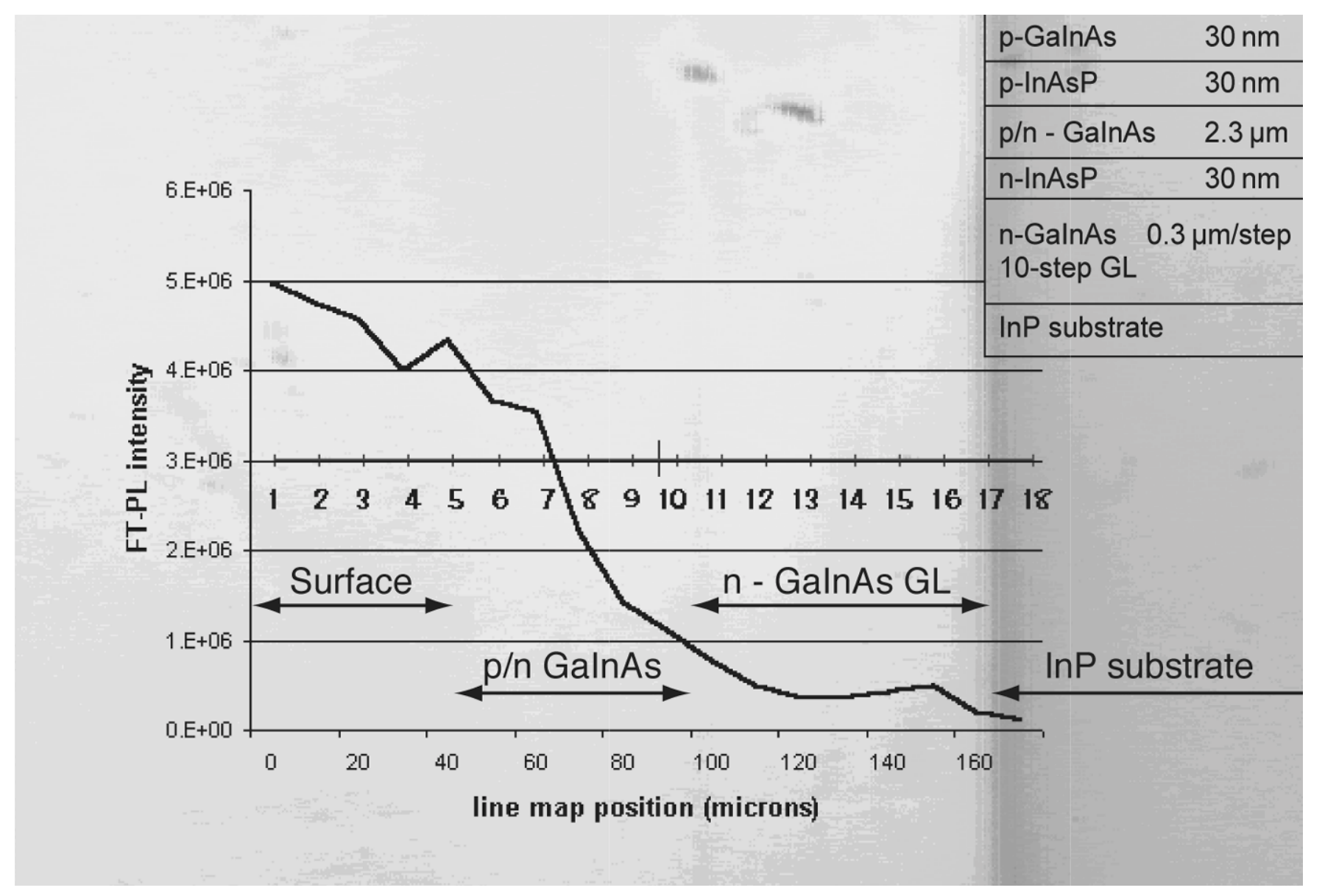

Figure 5. Linear scan positions and PL intensities measured at these positions for angle-lapped TPV device \#1-213, superimposed on a micrograph of the lapped device. The device structure and approximate regions on the lapped surface corresponding to the thickest device layers are also shown.

in the absorber layer, because the surface quality of the lapped region of the sample is inadequate to allow band bending [20]. PL intensity dropped rapidly as the GL was traversed, implying a relative increase in the rate of nonradiative recombination. No PL was collected from the final scan point, in the InP substrate.

Figure 6 is a three-dimensional plot of the corrected FT-PL spectra obtained from the linear scan of angle-lapped TPV device \#1-213, versus scan position in microns. The approximate locations of the thicker device layers are shown on the scan distance axis in Fig. 6. The decrease in PL intensity as the device structures were traversed during the scan, and the shift of the PL spectra to higher energies as the GL was traversed are clearly evident. The FWHM bandwidth of the spectra shown in Fig 6 varied only from $526 \mathrm{~cm}^{-1}$ for the $\mathrm{p} / \mathrm{n}$ absorber layer $(\mathrm{x}=0.32)$ to $543 \mathrm{~cm}^{-1}$ at the $\mathrm{GL} / \mathrm{InP}$ interface $(\mathrm{x}=0.47)$. The $543 \mathrm{~cm}^{-1}$ bandwidth measured at the $\mathrm{GL} / \mathrm{InP}$ interface during the scan is nearly twice that measured for $\mathrm{LM} \mathrm{Ga}_{0.47} \mathrm{In}_{0.53}$ As (Fig. 3). The $526 \mathrm{~cm}^{-1}$ bandwidth measured throughout the absorber layer during the scan is comparable to that measured at the cleaved edge of the absorber layer in this sample (Fig. 4). The nearly constant bandwidth calculated from the PL scan data implies that band filling was reasonably constant at the sample locations scanned. During this scan, only PL spectra characteristic of $\mathrm{Ga}_{\mathrm{x}} \mathrm{In}_{1-\mathrm{x}} \mathrm{As}$ were observed. Even with angle-lapping, the $32 \mathrm{x}$ objective has insufficient spatial resolution to collect 


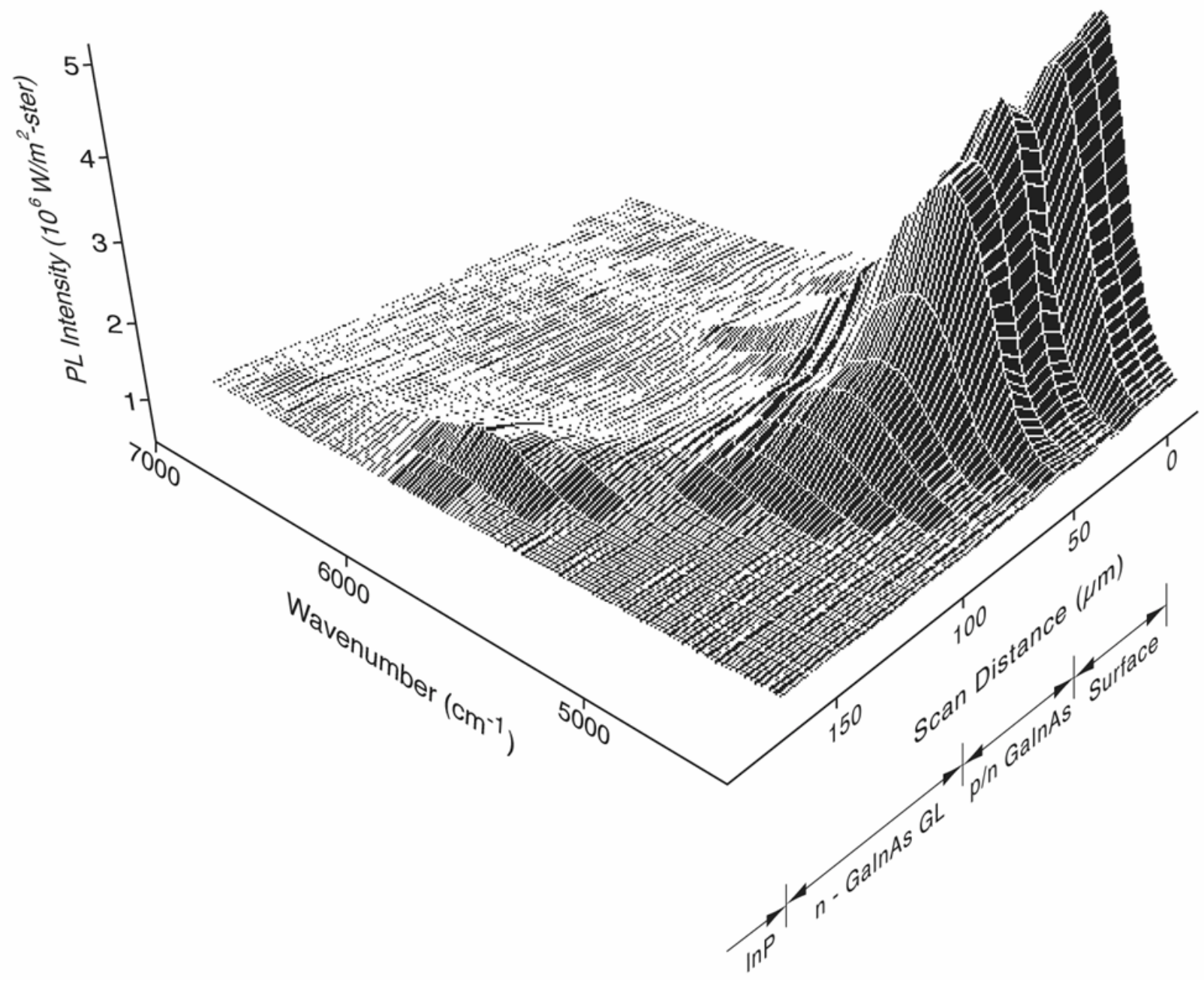

Figure 6. Three-dimensional plot of the corrected FT-PL spectra obtained from the linear scan of angle-lapped TPV device \#1-213, versus scan position in microns. The approximate locations of the thicker device layers are shown on the scan distance axis.

PL exclusively from the cap and confinement layers, and the confinement layer and substrate bandgaps are beyond the upper limit of the InSb detector response range. The detector cannot be switched to Ge during a scan with the current scanning software, although rescanning the sample at the same locations with the Ge detector is possible. Attempts to resolve PL from the confinement layers in the anglelapped device using the 100x objective with 1064-nm excitation, Ge detector, and manual joystick positioning of the lapped sample were not successful. Apparently the limited optical throughput of the 100x objective, the thinness of the confinement layer, or damage to the confinement layer during lapping reduced its PL signal below detection limits.

The energies of the corrected PL bands calculated for TPV device \#1-213 are plotted as a function of scan position, with the predicted $\mathrm{E}_{\mathrm{g}}(\mathrm{x})$ of the $\mathrm{Ga}_{\mathrm{x}} \mathrm{In}_{1-\mathrm{x}} \mathrm{As}$ device structure, in Fig. 7. We used the method of Bassignana, et al [24] to estimate the PL band energies as the energy at half of the band maximum intensity (measured on the low-energy side of the bands), rather than the energies of the PL band maxima. This approach minimizes the effect of variations in excitation density on the room-temperature 
PL measurements. The approximate scan regions corresponding to the thickest device layers are also shown in Fig. 7. There is a close correspondence between the PL band energies and the predicted

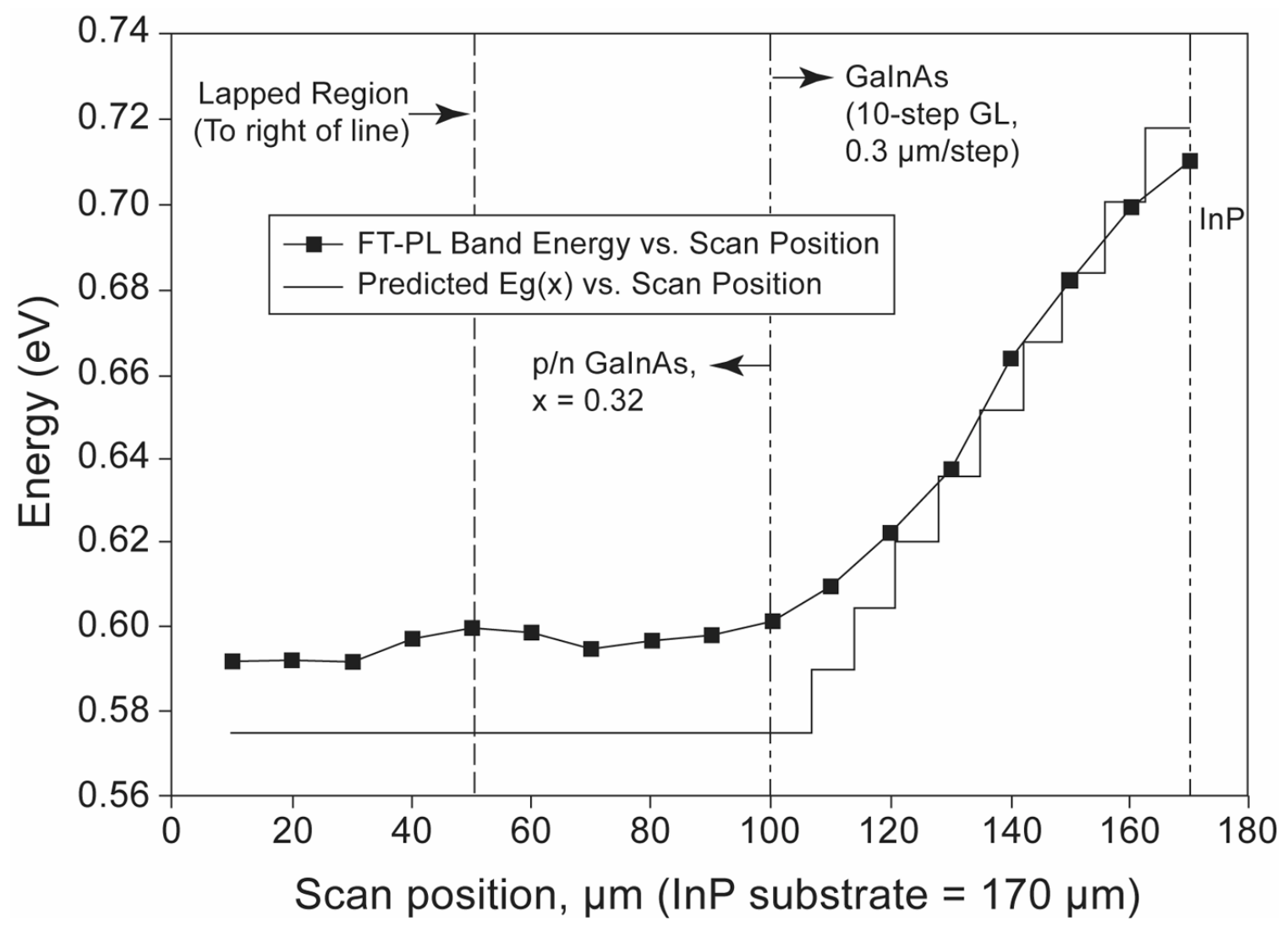

Figure 7. Band energies of the corrected PL spectra measured for TPV device \#1-213, plotted as a function of scan position, compared to the predicted $E_{g}(x)$ of the $G a_{x} I n_{1-x} A s$ device structure at these positions.

direct bandgap of unstrained, bulk $\mathrm{Ga}_{\mathrm{x}} \mathrm{In}_{1-\mathrm{x}} \mathrm{As}$ at $300^{\circ} \mathrm{C}[19]$,

$$
E_{g}(x)=\left(0.555 x^{2}+0.505 x+0.356\right)
$$

The value of $\mathrm{x}$ is constant at 0.32 in the absorber layer, and varies stepwise from 0.32 to 0.47 (InP-LM) in the GL of this sample. The PL band energies are greater by about $20-25 \mathrm{meV}$ in the absorber layer than the predicted values. Lattice strain in the biaxially compressed LMM layers [18] would be expected to increase the PL band energy [24], requiring modifications to the optical bowing parameters in Eq. (1) [19]. Allowing for these effects, the PL band energies track the predicted bandgap of the material closely, although the match is closer near the InP substrate. Also, the PL band energies plotted in Figure 7 "anticipate" the increase in $\mathrm{E}_{\mathrm{g}}(\mathrm{x})$ in the GL at the last scan position in the absorber layer (100 $\mu \mathrm{m})$, indicating that the excitation penetration depth may correspond to about a single scan interval, i.e., that the effective excitation depth at $1064 \mathrm{~nm}$ is approximately $\left[10 \mu \mathrm{m} \sin \left(2.5^{\circ}\right)\right]$, or about $0.4 \mu \mathrm{m}$. This depth corresponds almost exactly with the $1 / \alpha$ value of $0.42 \mu \mathrm{m}$ calculated from refractive index data for $\mathrm{Ga}_{0.3} \mathrm{In}_{0.7} \mathrm{As}$ [19]. The excitation depth is much shallower than the device thickness, so that the decrease 
in PL intensity observed as the lapped device is traversed (Figs. 5 and 6) is not simply a result of decreasing device thickness in the lapped region. The lower PL intensity observed as $\mathrm{x}$ increases from 0.32 in the absorber layer to 0.47 at the GL/InP interface (Figs. $4-6$ ) may be related to an increase in the relative rate of non-radiative surface recombination attendant to the shallower excitation depth of $0.21 \mu \mathrm{m}$ in $\mathrm{Ga}_{0.47} \mathrm{In}_{0.53} \mathrm{As}$ [19]. In addition to differences in recombination rates, this phenomenon could also explain some of the differences in PL intensity shown in Fig. 3. The observation that excitation density at constant excitation power varies as a function of material composition in $\mathrm{Ga}_{\mathrm{x}} \mathrm{In}_{1-\mathrm{x}} \mathrm{As}$ also serves to emphasize the importance of utilizing a reproducible method, as in [24], for calculating band energies from room temperature PL spectra.

\section{Conclusions}

The results of the series of experiments on CIGS samples have given us valuable insights into the nature of the CdS/CIGS interface and the role that cadmium plays in junction formation and passivation in thinfilm CIGS PV devices. Work is continuing to elucidate the nature of the $\mathrm{p} / \mathrm{n}$ junction in CIGS devices and to devise improved device manufacturing procedures yielding more efficient CIGS PV modules. The FT-PL technique has been extended to allow sample temperature control, alternate laser excitation sources, and full coverage of PL spectra for CIGS samples containing up to $30 \% \mathrm{Ga}\left(\mathrm{E}_{\mathrm{g}}=1.3 \mathrm{eV}\right)$. For III-V TPV device characterization, valuable information for tracking the optical bandgap and discerning the effects of LMM was obtained. Extension of the range of the FT-PL technique to energies as low as $0.46 \mathrm{eV}(2.7 \mu \mathrm{m})$ by addition of the $\mathrm{InSb}$ detector enables analysis of $\mathrm{Ga}_{\mathrm{x}} \mathrm{In}_{1-\mathrm{x}}$ As and other candidate TPV absorber materials. Addition of the scanning microscope to the Nicolet 960 FT-Raman system allows FT-PL line and area maps of semiconductor films to be collected at spatial resolutions of $10 \mu \mathrm{m}$ using the 32x objective. With the 100x objective, the microscope enables FT-PL analysis of selected areas at spatial resolution of $1-2 \mu \mathrm{m}$, which approaches the diffraction limit for the excitation radiation, and allows device-scale characterization of material composition and quality.

\section{References}

1. S. Q. Gu, D. Chen, J. M. Viner, M. E. Raikh, and P. C. Taylor, in R. Noufi (Ed.), AIP Conference Proc., Vol. 268, American Institute of Physics, New York, 1992, p. 363.

2. A. Yamada, M. Tanda, S. Manaka, H. Sano, M. Konegai, and K. Takahashi, in L. Guimaraes (Ed.), Proc. $11^{\text {th }}$ European Photovoltaic Solar Energy Conference, Harwood, Switzerland, 1992, p. 128.

3. R. K. Ahrenkiel, in R. K. Willardson and A. C. Beer (Eds.), Semiconductors and Semimetals, Vol. 39, Ch. 2, Academic Press, New York, 1993, p. 141.

4. R. K. Ahrenkiel, D. J. Dunlavy, B. M. Keyes, S. M. Vernon, S. P. Tobin, and T. M. Dixon, in Proc. $21^{\text {st }}$ IEEE Photovoltaic Specialists Conference, Institute of Electrical and Electronic Engineers, New York (1990), p. 432.

5. P.R Griffiths and J. A. De Haseth, Fourier Transform Infrared Spectroscopy, John Wiley \& Sons, New York, 1986.

6. K. Pressel, G. Ruckert, A. Dornen, and K. Thonke, Phys. Rev. B, 46, no. 20 (1992), p.13171.

7. J. P. Estrera, W. M. Duncan, Y. C. Kao, H. Y. Liu, P. D. Stevens, and E. A. Beam III, in Proc. SPIE, Vol. 1678, International Society for Optical Engineering, Bellingham, WA, 1992, p. 120.

8. G. Mauckner, K. Thonke, and R. Sauer, J. Phys: Condensed Matter, 5, no. 1 (1993), p. L9. 
9. N. L. Rowell, Proc. SPIE, Vol. 822, International Society for Optical Engineering, Bellingham, WA, 1987, p. 161.

10. J. D. Webb, D. J. Dunlavy, T. Ciszek, R. K. Ahrenkiel, M. W. Wanlass, R. Noufi, and S. M. Vernon, Appl. Spectrosc., 47, no. 11 (1993), 1814.

11. J. D. Webb, D. J. Dunlavy, T. Ciszek, R. K. Ahrenkiel, M. W. Wanlass, R. Noufi, and S. M. Vernon, in O. J. Glembocki (Ed.), Proc. Mat. Res. Soc. Symp., Vol. 324, Materials Research Society, Pittsburgh, 1994, p. 233.

12. J. D. Webb, M. Contreras, and R. Noufi, in D. J. Flood (Chair), Proc. $24^{\text {th }}$ IEEE Photovoltaic Specialists Conference, Institute of Electrical and Electronic Engineers, New York (1994), p. 275.

13. J. D. Webb, B. M. Keyes, K. Ramanathan, P. Dippo, D. W. Niles, and R. Noufi, in C. E. Witt (Ed.), Proc. AIP, Vol. 394, American Institute of Physics, Woodbury, New York, 1997, p. 573.

14. B. Schrader, in D. B. Chase and J. F. Rabolt (Eds.), Practical Fourier Transform Infrared Spectroscopy, Academic Press, New York, 1990, Chap. 4.

15. T. L. Wangensteen, M. W. Wanlass, J. J. Carapella, H. R. Moutinho, A.R. Mason, J. D. Webb, and F. A. Abulfotuh, in Proc. $26^{\text {th }}$ IEEE Photovoltaic Specialists Conference, Institute of Electrical and Electronic Engineers, New York (1997), p.967.

16. K. Ramanathan, M. A. Contreras, J. R. Tuttle, J. Keane, J. D. Webb, S. Asher, D. Niles, R,. Dhere, A. 1. Tennant, F. S. Hasoon, and R. Noufi, in Proc. $25^{\text {th }}$ IEEE Photovoltaic Specialists Conference, Institute of Electrical and Electronic Engineers, New York (1996), p.837.

17. L. C. Olsen, H. Aguilar, F. W. Addis, W. Lei, and J. Li, , in Proc. $25^{\text {th }}$ IEEE Photovoltaic Specialists Conference, Institute of Electrical and Electronic Engineers, New York (1996), p.997.

18. M. W. Wanlass, Solar Energy Materials and Solar Cells, 41/42 (1996), p. 405.

19. P. Bhattacharya (Ed.), Properties of Lattice-Matched and Strained Indium Gallium Arsenide, Short Run Press Ltd., Exeter, UK, 1993, pp. 252 (etch), 7 ( $\left.\mathrm{E}_{\mathrm{g}}(\mathrm{x})\right)$, and $188(\alpha)$.

20. R. A. Street, R. H. Williams, and R. S. Bauer, J. Vac. Sci. Tecnol. 17, no. 5 (1980), p. 1001.

21. K. Ramanathan, R. N. Bhattacharya, J. Granata, J. D. Webb, D. Niles, M. A. Contreras, H. Wiesner, F. S. Hasoon, and R. Noufi, in Proc. $26^{\text {th }}$ IEEE Photovoltaic Specialists Conference, Institute of Electrical and Electronic Engineers, New York (1997), p. 319.

22. A. Zegadi, M. V. Yakushev, E. Ahmed, M. A. Slifkin, A. E. Hill, and R.D. Tomlinson, in D. J. Flood (Chair), Proc. 24 ${ }^{\text {th }}$ IEEE Photovoltaic Specialists Conference, Institute of Electrical and Electronic Engineers, New York (1994), p. 226.

23. M. W. Wanlass, J. J. Carapella, A. Duda, K. Emery, L. Gedvilas, T. Moriarty, S. Ward, J. Webb, X. Wu, and C. S. Murray in Proc. $4^{\text {th }}$ NREL Conference on Thermophotovoltaic Generation of Electricity, AIP Conf. Proc. 460 (1998), p. 132.

24. I. C. Bassignana, C. J. Miner, and M. Puetz, J. Appl. Phys. 65, no. 11 1989), p. 4299. 